\title{
Investigating English Reading Comprehension Problems of Cambodian High School Students
}

\author{
Doung Dara \\ Huazhong University of Science and Technology \\ Wuhan 430074, P. R. China
}

\begin{abstract}
The objective of this paper is to investigate English reading comprehension problems of Cambodian high school students through mixed methods with 223 students ( excluded the $12^{\text {th }}$ graders) and 6 English teachers from the two high schools in Kep province as the direct responders. This study used questionnaire and interview as instruments for data collection while factor analysis and qualitative description as tools for data analysis and interpretation. The finding illustrated that lack of language knowledge and motivation were mostly carried out English reading problems while student personality, learning methods and teacher personalities were the shadow behind the issues even though the Ministry of Education Youth and Sport had integrated this subject into the state curriculums for lower secondary to tertiary educations since 1993. To take more actions for challenges, investigation of this issue at lower secondary school, additional root causes including family issues, English study time, learning and teaching materials, and library accesses were recommended for future research.
\end{abstract}

Keywords: English reading problem, High School Level, Shadow behind, Cambodia.

\section{1-Introduction}

\subsection{Background of the Research}

In 1993, Ministry of Education, Youth and Sports began to instigate English subject into the national curriculums from lower secondary school to tertiary education institutions (MoEYS, 2013), but the students' English abilities at high school levels are still limited according to the results of the 12th grade national examinations. Many researchers from different countries affirm that the weakness of language competency has a strong connection with reading problems (Marriam, Joy, \& Rebacca, 2003; Eskey, 2002; Do Minh \& Vo Phan, 2015). Relatively, reading comprehension problems can be affected by a number of factors namely lack of linguistic competency (Alderson, 1999; Sajeerat, 2011; Mikulecky, 2008; Bernhardt, 2005), learners' experiences or previous knowledge (Xu, 2006; Sajeerat, 2011; Alderson, 2000), lack of motivation (Sajeerat, 2011; Law, 2011; McGeown et al., 2015), lack of reading strategies (Sajeerat, 2011; Shokrpour \& Fotovatian, 2009; Rattanaseeha, 2007) and so on.

On the other hand, there has been little research conducted in Cambodia concerning with English reading issue. What has been found so far is just a few pieces of small articles pointing out the causes of the problems which might be related to English learning problems such as lack of authentic materials, the limitation of teachers' qualifications, poor learning environments, lacks motivations, etc. (MoEYS, 2013), but what causes high school students poor reading comprehension has not yet been fully identified. Of course, this problem is not a new topic for some countries, but it is still worth investigating in this country because there is a great lack of research findings that help to detect the problems, find out the causes and take effective measures to solve the problems for the purpose of improving the English teaching in Cambodia.

\subsection{Objective of the Research}

This research primarily aims to investigate the reading comprehension problems that the students in high school level have and hinder their abilities to understand the reading texts or materials. It also attempts to discover the causes which inhabit behind those problems. The solutions and pedagogical implications will be proposed and suggested for learning and teaching reading comprehensions.

\section{Literature Review}

\subsection{Definitions of reading comprehensions}

Reading comprehension is an interactive process between the text and the readers' background knowledge (Carrrell and Eisterhold, 1984). Some researchers call it as a process that involves not only recalling facts but also inference and evaluating the author's point of view (Noicharoen, 2012); 
Despite the fact that the definitions of reading comprehensions are highly documented and have been proposedly given. In this study reading comprehension targetively refers to the ultimate goal of every reading practice by using crucial processing skills which provide a reader reading, synthesis and appraisal competence.

\subsection{Reading Models}

A number of leading experts and specialists in reading field have developed many reading processes or models to promote reading outcomes of English learners at any level: firstly bottom-up which is able to build up basic units and sentential levels (Carroll, 1964; Rudell, 1969; Gough, 1972 cited in Xu,J 2016) and used to scan the smallest units (bottom) to the larger units (top) of linguistic components until the meaning can be explored entirely. Secondly, topdown is to earn more accurate assumptions (Goodman, 1967) which functions the best for higher levels, directing to skimming the gist of a text and this approach is a prosody by which language learners use schematic knowledge (i.e. linguistic knowledge and background information) that they have already known to make a good prediction of the text's meanings while performing their reading tasks (Dubin \& Bycina, 1991; Mikulecky, 2008). Thirdly, interactive model which coherently reveals how various language sources providing continuous inputs interact or compensate each other (Rumelhart, 1977; Stanovich, 1980). Grabe (1988) which cited in Aidinlou (2012) talked of three different senses for the term "interactive": reading as an interactive process, which focuses on the text-reader relations; interactive model of reading, which concentrates on the integration of lower- and higher- components of the reading process; and textual interactive reading, which involves those interactions with the text as a whole.

\subsection{Reading Strategies}

Palinscar and Brown (1984) highlighted only four needed reading strategies for explicit and direct strategy training of foreign language students: summarizing or self-reviewing, questioning, predicting, and clarifying. However, there were five frequently used reading strategies, firstly scanning is a reading technique that requires reader to search for specific information without reading the whole text, through looking at its title, the table of content and so on (Grellet ,1981, cited in Rouai Souhila, 2014). Secondly, skimming is a common technique in reading which the readers move their eyes rapidly over the text to gist and get a general overview of the content (Babaiba, 2015). Thirdly, predicting is a very useful way that the reader may use to predict about the text relying on his or her previous knowledge and extract the meaning of the text even if there exist unfamiliar words in the text (Babaiba, 2015). Fourthly, inferencing is a reading strategy that the readers have to read the between the lines to draw the conclusion (Keene, E. O., \& Zimmermann, S, 1997).Fifthly, summarization strategy is a reading comprehension strategy that consists of four steps: review the passage, evaluate the paragraph, answer with a paraphrase, and determine a passage summary and it can be quite mystifying and puzzling to students who are not familiar with it (Wormeli, 2005, cited in Pardis Safani, 2014).

\subsection{Common problems with English reading abilities}

Some researchers state that the factors that influence the reading comprehensions are the difficulties of materials, the readers' responses, background knowledge and experience in selecting reading books, the natures of readers and environments (Noicharoen,2012), the learners' susceptible comprehending of the text structure, conclusion drawing, and comprehension checking (Perfetti, Landi, \& Oakhill, 2004). Even though only some of them are leading and highly-frequently found such as lack of language knowledge, five commonly distinctive problems are found listing as the following: problem pertaining to poor background knowledge, problems pertaining to lack of motivation, problems pertaining to lack of reading strategies, and problems with poor decoding ability.

\subsection{Previous research on English reading problems}

There were much research on problems of English reading comprehension as the second language around the word (H.V.Chung, 2011; Nongnat.Ch, 2008; Pangsapa. N, 2012; Gilakjani \& Ahmadi, 2011; Azeroual, 2014; Al Seyabi \& Tuzlukova, 2015; Da Fontoura \& Siegel, 1995; Shehu, 2015; Koda, 1994). They focused on finding out the problems that caused readers not to understand the texts well. As the results, many factors had been shown to prevent readers ' comprehensions such as decoding, vocabulary, sentence structures, syntax, text types, background knowledge, text organizations. There were also studies on factors affecting reading comprehensions (Nergis, 2013; Sanford, 2015; Vaseghi, Barjesteh, \& Gholami, 2012; Gilakjani \& Sabouri, 2016). The findings demonstrated that there were several factors which impact on reading grasp such as reading strategies (cognitive and metacognitive), textual complication, environment conditions, anxieties, interests, encouragements, medical problems, or decoding, etc.

The study on sources of reading problems was discovered in the study of Yorio (1971). It suggested that there are several sources of the reading problems, for instance the difference of understanding levels between the first and second languages, the imperfect language knowledge, the uncertainty in language uses, the unfamiliarity of materials and lack of training, the interference from native language. Another relevant research is about the linguistic problems that block the reading comprehensions (Atikah, 2009). 
In this study, it aimed to observe merely linguistic problems such as vocabulary, spelling (decoding) and structure (syntax) of the second-grade students of MTs. Baiturrahmah Sukabumi and its results claimed that the students in these levels met all aspects of the linguistic problems.

\section{Research Methodology}

\subsection{Research Design}

Mixed method research was applied for this purposively interesting topic through the discussion with supervisor who was demonstrated all the research processes and procedures like verification of the gaps in topic, initiative literature reviews, the development of research instruments, validation, accuracy and reliability, data collection of both pilot data and actual data which were from the field and the implementation of factor analysis for finding out the supreme problems while qualitative data analysis for interpreting the results. In this study only two types of participants were opted to involve in. Moreover, solely 223 students by excluded the $12^{\text {th }}$ graders and 6 English teachers at two high schools in Kep province, Cambodia, were identified as straight responders.

\subsection{Instrument}

The questionnaires and interview were used as research instruments for data collection and these questionnaires were derived from the these research of Sajeerat W. (2011) which consisted of 20 items and were grouped into 5 different problems with 5-likert scale as an evaluation system that number 1 means "strongly disagree" and 5 means "strongly agree". The interview questions were developed after getting the results from questionnaires to be used for gathering more information for additional interpretation of results. Those semi-constructed interview questions were consisted of two main sub-sections - for students and teachers with different questions and purposes.

\subsection{Data Collection Procedure}

In order to collect the data, formal letters of permission was sent to school principals for their consents to allow for data collecting at the target school levels. When their notices of agreements returned, the questionnaires were distributed to the students and they had to return these questionnaires to their class monitors within a week. After questionnaire collection, data were input and computerized to analyze with factor analysis in order to discover the most prevailing factors or problems. From these results, the interview questions were devised for further investigations to find threads of evidence or reasons to sustain the first result. Later, interview were conducted and the data were collected.

\section{Data Analysis}

From the sample of 223 students, the Cronbach's Alpha of all the 18 items in the five scales is 0.5836 , which indicated that the questionnaire was reliable as a whole and the items in each scale have relatively good internal consistency and it can be assumed that lack of language knowledge and motivation are main problems of Cambodian high school students in English reading comprehensions.

\begin{tabular}{|l|l|l|}
\hline Factor & N of Items & Cronbach's Alpha \\
\hline Lack of language knowledge & 5 & 0.704 \\
\hline Lack of motivation & 4 & 0.66 \\
\hline Reading Strategies & 4 & 0.552 \\
\hline Poor reading process & 2 & 0.576 \\
\hline Background Knowledge & 3 & 0.426 \\
\hline Total & 18 & 0.5836 \\
\hline
\end{tabular}

Responding to the question "Can you understand the reading texts well?" 65.00 percent of students provided information that they did not understand the reading text because it had complex grammar, difficult vocabulary, technical words and sentence structure; and teachers did not provide specific reading techniques, explain about reading passage with additional example but share experience but just showing how to pronounce new vocabularies, translating technical words to Khmer language, arranging group discussion activity and managing student to check new word by using dictionary and parts of speech.

Teachers expressed that generally there were around 40 to 48 students in one class, which was the crowded and difficult number to manage teaching activities and to follow up previous lesson. These matters also came along with the students' lack of basic knowledge of English, not-reading or not-wanting -to- read culture; shyness or uncooperative work, whereas their families did not encourage them to study hard or uphold futuristic. In addition, some teachers blamed themselves that their teaching techniques were not good enough for improving students' reading competency because students needed much more than what they could have provided. 


\section{Discussion}

According to Sajeerat (2011) demonstrated that background knowledge, lack of motivation, lack of reading strategy, background knowledge and the language knowledge were in order issues which students at Mathayom in Thailand challenged in English reading while vocabulary, working memory, absence of extensive reading and text types were indicted as an issues in Croatia after studied by Irena Shuhu in 2015 and these results were similar to Nongnat,Ch (2008) who had investigated English reading problems of the Thai grade $12^{\text {th }}$ students. While, Yingjie,Y (2016) found that the ESL or EFL readers met some internal problems as the follow: anxiety, confidence, instruction, guidance and Linda,B (2014) indicated more factors impacted to readers such as weak decoding, poor reading prosodies, weak language processing skills, poor vocabulary, memory issues and lack of active process.

In comparing this study with other previous research indicated that lack of language knowledge and motivation were the factors that effected to English reading comprehension of the students while student-related and teacher-related factors were an obstacle behind those problems. Peterson, et al. (2000) advised that in order to build reading proficiency at the secondary levels, motivation to read, ability to decode print, ability to comprehend language, and the ability to transact with text (to actively seek information and make personal response) should be core strategies.

\section{Conclusion and Recommendation}

\subsection{Conclusion}

The aims of this study is to investigate the reading comprehension problems that Cambodian high school students have currently challenged and what have hindered their abilities to understand the reading texts or materials and it also attempts to discover the causes which inhabit behind those problems. Based on the quantitative data analysis result, lack of language knowledge and motivation were mostly carried out English reading comprehension problems while student personality, learning methods and teacher personalities were the shadow at the heels.

\subsection{Recommendation}

Thanking to the findings, some recommendations for the future research in order to solve the reading comprehension issues which Cambodian high school students have faced are as below:

- English reading problems of Cambodian lower secondary school students had been recommended for future research. Conducting investigation at this stage will be provided more new strategies for ministry as relevant stakeholders to take on-time actions for English reading issues.

- The root cause which affected on reading comprehension such as family issue, English study time, learning and teaching material, library access, and so on should be included as a factors for future research.

\section{References}

Aidinlou, N. A. (2012). An SFL-oriented framework for the teaching of reading in EFL context. International Journal of English Linguistics, 2(1), 207.

Al Seyabi, F., \& Tuzlukova, V. (2015). Investigating EFL Reading Problems and Strategies in Post-Basic Schools and University Foundation Programmes: A Study in the Omani Context. Malaysian Journal of ELT Research, $11(2), 35$.

Alderson, C. J. (2000). Assessing Reading. The United Kingdom: Cambridge University

Anderson, N. J., \& Cheng, X. (1999). Exploring second language reading: Issues and strategies: Heinle \& Heinle Boston, MA.

Atikah, I. (2009). Analysis on the students' linguistic problems in reading comprehension :(a case study at second grade students of MTs. Baiturrahmah Sukabumi).

Azeroual, D. (2014). Investigating the Reading Difficulties of Magister Students of Physics vis-à-vis Their General English knowledge, University of Constantine. Revue Sciences Humaines(41), 89-98.

Babaiba, W. (2015). Reading Comprehension Difficulties among EFL Learners: The Case of Third-Year Learners at Nehali Mohamed Secondary School.

Bernhardt, E. (2005). Progress and procrastination in second language reading. Annual review of applied linguistics, 25, 133-150.

Carrell, P. L. (1984). Schema theory and ESL reading: Classroom implications and applications. The Modern Language Journal, 68(4), 332-343.

Da Fontoura, H. A., \& Siegel, L. S. (1995). Reading, syntactic, and working memory skills of bilingual PortugueseEnglish Canadian children. Reading and Writing, 7(1), 139-153. 
Dubin, F., \& Bycina, D. (1991). Models of the process of reading. Teaching English as a Second or Foreign Language. Boston, Mass.: Heinle and Heinle.

Gilakjani, A. P., \& Ahmadi, S. M. (2011). The Relationship between L2 Reading Comprehensionand Schema Theory: A Matter of Text Familiarity. International Journal of Information and Education Technology, 1(2), 142.

Goodman, K. S. (1967). Reading: A psycholinguistic guessing game. Literacy Research and Instruction, 6(4), 126-135.

Keene, E. O., \& Zimmermann, S. (1997). Mosaic of thought: Teaching comprehension in a reader's workshop: ERIC.

Koda, K. (1994). Second language reading research: Problems and possibilities. Applied psycholinguistics, 15(01), 128.

Law, Y. K. (2011). The effects of cooperative learning on enhancing Hong Kong fifth graders' achievement goals, autonomous motivation and reading proficiency. Journal of Research in Reading, 34(4), 402-425.

Linda Balsiger, M.S. Reading comprehension--reading but not understanding. Retrieved by www.bendlanguageandlearning .com.

McGeown, S. P., Duncan, L. G., Griffiths, Y. M., \& Stothard, S. E. (2015). Exploring the relationship between adolescent's reading skills, reading motivation and reading habits. Reading and Writing, 28(4), 545-569.

Mikulecky, B. S. (2008). Teaching reading in a second language. Recuperado de http://longmanhomeusa. com.

MoEYS. (2013). Curriculum framework of general education and technical education. Department of Curriculum Development.

Nergis, A. (2013). Exploring the factors that affect reading comprehension of EAP learners. Journal of English for Academic Purposes, 12(1), 1-9.

Noicharoen, C. (2012). An Investigtion of 11 the grade Thai student s' decoding strategeis at the word level in Englis reading. Srinakharinwirot university .

Nongnat, Ch. 2008. [M]. An investigation of English reading problems of Thai 12th grade students in Nakorachasima Educational region 1,2,3 and 7. Srinakharinwirot University, Bangkok.

Palinscar, A. S., \& Brown, A. L. (1984). Reciprocal teaching of comprehension-fostering and comprehensionmonitoring activities. Cognition and instruction, 1(2), 117-175.

Pangsapa,N. (2012).[M].A study of English reading problems and strategies of Thai editorial staff. Srinakharinwirot University, Bangkok.

Perfetti, C., McKeown, M., \& Kucan, L. (2010). Decoding, vocabulary, and comprehension. Bringing reading research to life, 291-303.

Peterson, et al. (2000). Building Reading Proficiency at the Secondary Level: A Guide to Resource. Southwest Educational Development Laboratory. Press

Sajeerat.W.2011. A survey study of English reading comprehension problems in academic texts as perceived by Mathayom 5 students in the English program at Thai Christian church. Thamasat University, Bangkok.

Sanford, K. L. (2015). Factors affecting the reading comprehension of secondary students with disabilities. University of San Francisco.

Shehu, I. (2015). Reading Comprehension Problems Encountered by Foreign Language Students, Case Study: Albania, Croatia. Academic Journal of Interdisciplinary Studies, 4(1 S1), 91.

Souhila, R. (2014). The Use of Reading Strategies in Improving Reading Comprehension: the case of first year LMD English students. Unpublished Master Thesis. Department of Foreign Languages. University Kasdi Merbah Ouargla.

Vaseghi, R., Barjesteh, H., \& Gholami, R. (2012). Critical thinking: An influential factor in developing English reading comprehension performance. Advances in Asian Social Science, 2(1), 401-410.

$\mathrm{Xu}, \mathrm{J}$. (2006). The theory and practice of modern foreign language teaching: 华中科技大学出版社.

Yang, Jie.( 2015). The Analysis of Tom's Personality in the Mill on the Floss Based on the Transitivity System.

Yorio, C. A. (1971). Some sources of reading problems for foreign-language learners. Language learning, 21(1), 107115 . 